\title{
PENERAPAN METODE BAYES DALAM MENGESTIMASI PREMI KREDIBILITAS PADA ASURANSI UMUM
}

\author{
Rain Fernando Bangun ${ }^{1 \S}$, I Nyoman Widana ${ }^{2}$, Desak Putu Eka Nilakusmaw ati ${ }^{3}$
}

\begin{abstract}
${ }^{1}$ Program Studi Matematika, Fakultas MIPA, Universitas Udayana [Email: bangunrainfernando @ gmail.com] ${ }^{2}$ Program Studi Matematika, Fakultas MIPA, Universitas Udayana [Email: widana @ unud.ac.id] ${ }^{3}$ Program Studi Matematika, Fakultas MIPA, Universitas Udayana [Email: nilakus mawati@ unud.ac.id] ${ }^{\S}$ Corresponding Author
\end{abstract}

\begin{abstract}
Determination of insurance premiums is very important the calculation must be done carefully so that there is experience losses. The purpose of this research is to find out the application of empirical Bayes credibility theory Model 1 and estimate of the credibility premium on general insurance. A method that can help in overcoming these problems, that is empirical Bayes credibility theory Model 1, results of the estimated credibility premium credibility (in Euros) for insurance companies Alianz, Csob, Generali, Koop, Unisqa, and Wusten respectively as follows: 46.774811, 7.801307, 10.368991, 58.812250, 6.703035, and 5.091605. These results, the average claim is greater than the credibility premium, so that insurance companies can reserve premiums for the future.
\end{abstract}

Keywords: Credibility Premium, EBCT Model 1, Credibility factor.

\section{PENDAHULUAN}

Asuransi umum atau general insurance adalah asuransi yang memberikan ganti rugi kepada anggota yang mengikuti asuransi jika terjadi kerugian pada harta benda. Contoh kerugian yang mungkin dialami oleh seseorang adalah kebakaran, kerusakan, kecelakaan, kehilangan, dan lain-lain.

Menurut Otoritas Jasa Keuangan (2019) asuransi umum merupakan asuransi yang memberikan jaminan terhadap kerugian yang terjadi pada harta benda, baik harta benda yang bergerak maupun yang tidak bergerak, serta memberikan jaminan tanggung jawab hukum kepada pihak ketiga yang mengalami kerugian. Asuransi umum memiliki banyak jenis, antara lain: asuransi kebakaran, kendaraan bermotor, pengangkutan, perjalanan, rangka kapal, perkebunan, pertanian, pesaw at terbang, satelit, tanggung jawab hukum pihak ketiga, mesin dan berbagai risiko kerugian aset lainnya.

Dalam asuransi umum maupun asuransi lainnya, perusahan asuransi akan membayarkan sejumlah uang apabila terjadi klaim dari anggota asuransi yang disebut benefit. Sedangkan anggota asuransi wajib membayarkan sejumlah uang yang disebut dengan premi ke perusahaan asuransi.
Penentuan premi merupakan hal yang krusial bagi perusahan asuransi. Oleh karena itu, perhitungan premi dan penentuan premi harus dilakukan dengan cermat dan teliti agar perusahaan asuransi tidak mengalami kerugian (Pham, 2014).

Berkenaan dengan hal tersebut, terdapat suatu teori yang biasanya digunakan oleh aktuaris dalam mengestimasi harga premi berdasarkan pengalaman klaim pada masa lalu, yaitu teori kredibilitas (Herzog, 1996). Teori kredibilitas adalah suatu teknik yang dapat mengetahui besar premi di masa depan berdasarkan data pengalaman di masa lalu (Satyahadewi \& Mara, 2013).

Dalam teori kredibilitas terdapat faktor kredibilitas dengan 3 pendekatan diantaranya, pendekatan kredibilitas fluktuasi terbatas, pendekatan bayesian dan pendekatan keakuratan terbesar (Satyahadewi \& Mara, 2013). Pada pendekatan kredibilitas fluktuasi terbatas, jika dilakukan estimasi, pendekatan memiliki faktor kredibilitas bernilai sama dengan 1 jika pengamatan dilakukan cukup besar. Pendekatan bayesian jika dilakukan estimasi, pendekatan yang menggabungkan seluruh pengamatan yang diperoleh dari informasi awal untuk memperoleh hasil 
pengamatan terbaik. Pada pendekatan kredibilitas keakuratan terbesar, jika dilakukan estimasi, pendekatan akan diperoleh dengan meminimumkan kuadrat antar nilai harapan dan varians yang diduga.

Dalam teori kredibilitas, terdapat banyak jenis metode dengan berbagai tingkat kompleksitas yang telah dikembangkan untuk dapat digunakan dalam mengestimasi harga premi pada masa depan, salah satunya yaitu empirical Bayes credibility theory atau teori kredibilitas Bayes empiris (Chukwudum, 2018). Keuntungan utama dari metode empirical Bayes credibility theory adalah model tersebut memiliki kegunaan dalam perhitungan premi tanpa harus mengetahui distribusi dari variabel acaknya.

Berkaitan dengan itu, penelitian dengan menerapkan metode empirical Bayes credibility theory pernah dilakukan oleh Chukwudum (2018) untuk mengestimasi harga premi kredibilitas asuransi bisnis tahun 2014 di Nigeria menggunakan empirical Bayes credibility theory Model 1 dimana lima kelas risiko yaitu portofolio kebakaran, kecelakaan, mesin, kelautan, serta minyak dan gas diamati. Dalam penelitian tersebut hasil estimasi premi kredibilitas digunakan untuk memberikan gambaran bagi perusahaan asuransi terkait cadangan yang perlu disiapkan perusahaan asuransi dalam mengantisipasi kemungkinan klaim yang lebih banyak. Lebih lanjut lagi, peneliti serupa pernah dilakukan oleh Linda \& Kubanova (2012) mengestimasi harga premi kendaraan bermotor dengan menggunakan data yang diperoleh dari perusahaan asuransi di negara Ceko dan Slowakia menggunakan empirical Bayes credibility theory Model 2, dan hasil yang diperoleh memberi gambaran mengenai ukuran dari setiap premi kredibilitas yang lebih besar.

Berdasarkan uraian di atas serta penelitianpenelitian terdahulu, penulis tertarik melakukan kajian menganalisis data yang bersumber dari artikel Linda \& Kubanova (2012) guna mengestimasi premi kredibilitas dengan menggunakan metode empirical Bayes credibility theory Model 1. Model 1 merupakan model yang paling sederhana yang digunakan sebagai gambaran tentang prinsip kerja empirical bayes credibility theory dalam menganalisis, yang betujuan untuk mengetahui penerapan tentang metode empirical Bayes credibility theory Model 1 dalam menentukan besar nilai premi kredibilitas asuransi kendaraan bermotor yang harus dibayar kepada perusahaan asuransi yang ada di negara Ceko dan Slow akia.

\section{METODE PENELITIAN}

\subsection{Jenis dan Sumber Data}

Sumber data yang digunakan dalam penelitian ini adalah data sekunder yang bersumber dari penelitian Linda \& Kubanova (2012). Data dari enam perusahaan asuransi umum di negara Ceko dan Slowakia ini merupakan data nilai premi kredibilitas pengguna kendaraan bermotor yang dibayarkan perusahaan asuransi pada tahun 2006-2010.

\subsection{Langkah Penelitian}

Adapun langkah-langkah yang dilakukan untuk mengestimasi harga premi kredibilitas pada perusahaan di negara Ceko dan Slowakia adalah:

1. Mengestimasi besar rata-rata keseluruhan ekspektasi klaim

a. Menghitung nilai rata-rata ekspektasi klaim $\bar{y}_{i}$ dari enam perusahaan asuransi di negara Ceko dan Slowakia menggunakan persamaan

$$
\bar{y}_{i}=\sum_{j=1}^{n} \frac{y_{i j}}{n}
$$

$i$ adalah perusahaan asuransi, $j$ adalah kolom setiap tahun, $y_{i j}$ adalah klaim setiap tahu ke tahun dari risiko setiap perusahaan asuransi

b. Mengestimasi keseluruhan nilai rata rata keseluruhan ekspektasi klaim dari enam perusahaan asuransi di negara Ceko dan Slowakia menggunakan persamaan

$$
\bar{y}=\frac{\sum_{i=1}^{N} \bar{y}_{i}}{N}
$$

$\bar{y}$ rata-rata keseluruhan dari semua risiko yang digabungkan.

2. Mengestimasi nilai harapan dari varians

a. Menghitung nilai varians dari enam perusahaan asuransi di negara Ceko dan Slowakia menggunakan persamaan

$$
\widehat{s^{2}}{ }_{1}=\frac{1}{n-1} \sum_{j=1}^{n}\left(Y_{i j}-\bar{Y}_{i}\right)^{2}
$$

b. Mengestimasi nilai harapan dari varians menggunakan

$$
\operatorname{est}\left[s^{2}(\theta)\right]=\frac{1}{N} \sum_{i=1}^{N}\left(\frac{\sum_{j=1}^{n}\left(y_{i j}-\bar{y}_{i}\right)^{2}}{n-1}\right)
$$


Hal ini, mewakili rata-rata varians klaim dalam risiko. Istilah dalam tanda kurung di sisi kanan persamaan mewakili varians dari setiap risiko.

3. Mengestimasi varians dari rata-rata yang diduga

a. Menghitung rata-rata yang diduga dari enam perusahaan asuransi di negara Ceko dan Slowakia menggunakan persamaan

$$
\widehat{\operatorname{Var}}\left(\bar{y}_{i}\right)=\frac{1}{(N-1)} \sum_{i=1}^{n}\left(\bar{Y}_{i}-\bar{Y}\right)^{2}
$$

b. Mengestimasi varians dari rata-rata yang diduga dengan menggunakan persamaan pada

$$
\begin{aligned}
\operatorname{Var}[m(\theta)] \frac{\sum_{j=1}^{n}\left(y_{i j}-\bar{y}_{i}\right)^{2}}{N n} & -\frac{1}{N n} \sum_{i=1}^{N}\left(\frac{\sum_{j=1}^{n}\left(\left(y_{i j}-\bar{y}_{i}\right)^{2}\right)}{n-1}\right)
\end{aligned}
$$

Ini mewakili varians dari klaim rata-rata antara risiko.

4. Mengestimasi harga premi kredibilitas untuk enam perusahaan asuransi di negara Ceko dan Slowakia

a. Menentukan besar faktor kredibilitas (Z) menggunakan persamaan

$$
Z=\frac{n}{n+\frac{E\left[s^{2} \theta\right]}{\operatorname{Var}(m(\theta))}}
$$

b. Mengestimasi besar premi kredibilitas $(E(m(\theta) / y))$ pada empirical Bayes credibility Model 1 menggunakan persamaan pada

5. Interpretasi hasil.

$$
E(m(\theta) / \bar{y})=Z \bar{y}_{i}+(1-Z) E(m(\theta)
$$

Pada metode empirical bayes credibility theory yang disampaikan oleh Chukwudum (2018), yaitu:

1. Z selalu bernilai interval 0 dan 1 ,

2. $\mathrm{Z}$ adalah fungsi yang meningkat dari $\mathrm{n}$. Hal ini menyatakan bahwa jika terdapat lebih banyak data dibandingkan kredibilitas,

3. $\mathrm{Z}$ adalah fungsi penurunan dari $E\left(\mathrm{~s}^{2}(\theta)\right)$ Oleh karena itu jika $E\left(\mathrm{~s}^{2}(\theta)\right)$ lebih tinggi nilainya dibandingkan dengan $\operatorname{var}(m(\theta))$ data dari kredibilitas akan lebih bervariasi jika dibandingkan dengan data dari kredibilitas lain,

4. $\mathrm{Z}$ adalah fungsi yang meningkat dari $\operatorname{var}(m(\theta))$. Oleh karena itu, jika nilai $\operatorname{var}(m(\theta))$ lebih tinggi dibandingkan dengan $E\left(s^{2}(\theta)\right)$ akan terdapat lebih banyak variabilitas antara berbagai kredibilitas dalam kolektif (gabungan) dan akan mengakibatkan lebih kecil kemungkinan bahwa kredibilitas lain dalam kolektif akan menyerupai kredibilitas yang menarik.

Adapun asumsi empirical bayes credibility theory model 1 sebagai berikut

1. Distribusi masing-masing bergantung pada parameter $\theta$. Nilai $\theta$ tetap (dan sama untuk semua) tetapi tidak diketahui.

2. Diberikan $\theta$ yang bersifat independen dan identik didistribusikan (iid).

3. Untuk risiko $\mathrm{i} \neq \mathrm{j}$ yang berbeda, pasangan $\left(\theta_{i}, y_{i j}\right)$ dan $\left(\theta_{k}, y_{k m}\right)$ adalah iid.

Parameter $\theta$ adalah parameter kredibilitas, yang terrmasuk bilangan real atau kuantitas yang lebih umum seperti satu bilangan real.

Salah satu sifat estimator yang baik adalah tidak bias. Sebuah penduga $\theta$ tidak bias jika $E$ $[\theta]=\theta$. Hal ini menyatakan bahwa adanya perbedaan antara nilai harapan penduga dan nilai sebenarnya dari parameter yang diestimasi harus nol yaitu $E[\theta]-\theta=\theta$.

\section{HASIL DAN PEMBAHASAN}

Empirical Bayes credibility theory Model 1 ini diterapkan berdasarkan data klaim bersih selama 5 tahun (2006-2010) pada perusahan asuransi di negara Ceko dan Slowakia. Data ini diperoleh dari jurnal Linda \& Kubanova (2012) dan disajikan pada Tabel 1 .

Tabel 1.Total Klaim (Jutaan Euro)

\begin{tabular}{|l|l|l|l|l|l|}
\hline Perusahaan & \multicolumn{5}{|c|}{ Tahun ke-j } \\
\cline { 2 - 6 } $\begin{array}{c}\text { asuransi } \\
\text { ke-i }\end{array}$ & 2006 & 2007 & 2008 & 2009 & 2010 \\
\hline Allianz & 45,82 & 43,75 & 51,48 & 52,21 & 47,4 \\
\hline Csob & 4,88 & 3,81 & 2,66 & 2,31 & 2,19 \\
\hline Generali & 2,44 & 3,08 & 12,60 & 13,1 & 17,19 \\
\hline Koop & 43,40 & 55,10 & 67,74 & 72,09 & 65,91 \\
\hline Uniqa & 2,18 & 3,66 & 6,01 & 7,99 & 9,21 \\
\hline Wusten & 4,88 & 4,40 & 4,88 & 2,4 & 3,98 \\
\hline
\end{tabular}

Sumber: Data diolah (2021)

Rata-rata dari ekspektasi klaim untuk enam perusahaan asuransi di negara Ceko dan Slowakia juga dapat dihitung yang tersaji pada Tabel 2. 
Tabel 2 Rata-rata Ekspektasi Klaim

\begin{tabular}{|l|c|}
\hline Perusahaan asuransi & $\bar{y}_{i}$ \\
\hline Allianz & 48,132 \\
\hline Csob & 3,170 \\
\hline Generali & 9,682 \\
\hline Koop & 60,848 \\
\hline Uniqa & 5,810 \\
\hline Wusten & 4,108 \\
\hline
\end{tabular}

Sumber: Data diolah (2021)

Setelah nilai rata-rata ekspektasi klaim masing-masing perusahaan asuransi telah diketahui, dan berdasarkan Tabel 1 diketahui bahwa perusahaan asuransi memiliki $\mathrm{N}$ (banyaknya perusahaan asuransi) $=6$, Selanjutnya, estimasi nilai rata-rata keseluruhan ekspektasi klaim akan dihitung.

Rata-rata keseluruhan ekspektasi klaim enam perusahaan di negara Ceko dan Slow akia:

$$
\begin{aligned}
\text { est } E(m(\theta)) & =\bar{y} \\
& =\frac{\sum_{i=1}^{N} \bar{y}_{i}}{N} \\
& =\frac{\sum_{i=1}^{6} \bar{y}_{i}}{6} \\
& =\frac{48,132+3,170+9,682+\cdots}{6} \\
& =21,958
\end{aligned}
$$

Dengan demikian diperoleh hasil dari eetimasi rata-rata keseluruhan ekspektasi klaim adalah 21,958. Selanjutnya, varians untuk enam perusahaan asuransi di negara Ceko dan Slowakia juga dapat dihitung yang tersaji pada Tabel 3.

Tabel 3. Varians

\begin{tabular}{|l|c|}
\hline Perusahaan asuransi & $\hat{s}_{i}^{2}$ \\
\hline Allianz & 13,230 \\
\hline Csob & 1,323 \\
\hline Generali & 43,150 \\
\hline Koop & 134,244 \\
\hline Uniqa & 8,537 \\
\hline Wusten & 1,052 \\
\hline
\end{tabular}

Sumber: Data diolah (2021)

Nilai harapan dari varians adalah rata-rata varians dari setiap perusahaan asuransi di negara Ceko dan Slowakia. Nilai harapan dari varians untuk enam perusahan di negara Ceko dan Slow akia:

$$
\text { est } E\left(s^{2}(\theta)\right)=\frac{1}{N} \sum_{i=1}^{N}\left(\frac{\sum_{j=1}^{n}\left(y_{i j}-\bar{y}_{i}\right)^{2}}{n-1}\right)
$$

$$
\begin{gathered}
=\frac{1}{6} \sum_{i=1}^{6}\left(\frac{\sum_{j=1}^{5}\left(y_{i j}-\bar{y}_{i}\right)^{2}}{5-1}\right) \\
=\frac{(13,230+1,323+43,150+\cdots)}{6} \\
=\frac{1}{6}(201,539) \\
=33,589
\end{gathered}
$$

Dengan demikian diperoleh hasil dari Nilai harapan dari varians adalah 33,589. Selanjutnya, nilai rata-rata yang diduga untuk enam perusahaan asuransi di negara Ceko dan Slow akia.

Tabel 4. Nilai Rata-rata yang Diduga

\begin{tabular}{|l|c|}
\hline Perusahaan asuransi & $\widehat{\operatorname{Var}}\left(\bar{y}_{i}\right)$ \\
\hline Allianz & 137,012 \\
\hline Csob & 70,600 \\
\hline Generali & 30,141 \\
\hline Koop & 302,481 \\
\hline Uniqa & 52,153 \\
\hline Wusten & 63,726 \\
\hline \multicolumn{2}{|l|}{ Sumber: Data diolah (2021) }
\end{tabular}

Varians dari rata-rata yang diduga adalah mean dari rata-rata yang diduga dari setiap perusahaan asuransi di negara Ceko dan Slowakia, yang dihitung sebagai berikut.

$$
\begin{aligned}
\operatorname{Var}(m(\theta))= & \frac{\sum_{i=1}^{N}\left(\bar{y}_{i}-\bar{y}^{2}\right.}{N-1}-\frac{1}{N n} \sum_{i=1}^{N}\left(\frac{\sum_{j=1}^{n}\left(\left(y_{i j}-\overline{y_{i}}\right)^{2}\right)}{n-1}\right) \\
= & \frac{\sum_{i=1}^{6}\left(\overline{y_{i}}-\bar{y}\right)^{2}}{6-1}-\frac{1}{65} \sum_{i=1}^{6}\left(\frac{\sum_{j=1}^{5}\left(\left(y_{i j-} \bar{y}_{i}\right)^{2}\right)}{5-1}\right) \\
= & (137,012+70,600+\ldots+63,726) \\
& \quad-\frac{1}{65}(13,230+1,323+\ldots+1,052) \\
= & 656,115-\frac{1}{65} * 201,539 \\
= & 655,599
\end{aligned}
$$

Dengan demikian diperoleh hasil dari varians dari rata-rata yang diduga adalah 655,599 . Selanjutnya, untuk dapat mengestimasi harga premi kredibilitas yang harus dibayarkan kepada enam perusahaan asuransi di negara Ceko dan Slowakia, terlebih dahulu akan dihitung nilai dari faktor kredibilitas $(Z)$.

Faktor kredibilitas untuk enam perusahaan asuransi di negara Ceko dan Slowakia adalah

$$
\begin{aligned}
Z & =\frac{n}{n+\frac{\operatorname{Est} E\left(s^{2}(\theta)\right)}{\operatorname{Var}(m(\theta))}} \\
& =\frac{5}{5+\frac{33,589}{655,599}} \\
& =0,989
\end{aligned}
$$


Setelah diperoleh hasil dari besar faktor kredibilitas, maka besar harga premi kredibilitas dari enam perusahaan asuransi di negara Ceko dan Slowakia dapat diestimasi. Premi Kredibilitas untuk enam perusahaan asuransi di negara Ceko dan Slowakia juga dapat dihitung yang tersaji pada pada Tabel 5 .

Tabel 5. Premi Kredibilitas

\begin{tabular}{|l|l|}
\hline Perusahaan asuransi & Premi kredibilitas \\
\hline Allianz & 47,866 \\
\hline Csob & 3,360 \\
\hline Generali & 9,806 \\
\hline Koop & 60,453 \\
\hline Uniqa & 5,973 \\
\hline Wusten & 4,289 \\
\hline
\end{tabular}

Sumber: Data diolah (2021)

Selanjutnya diperoleh hasil dari premi kredibilitas dan ekspektasi klaim dari setiap perusaan di negara Ceko dan Slowakia, menunjukkan bahwa ekspektasi klaim lebih besar dibandingkan dengan premi kredibilitas yang yang tersaji pada pada Tabel 6 .

Tabel 6. Premi Kredibilitas Rata-rata ekspektasi klaim

\begin{tabular}{|l|l|l|}
\hline $\begin{array}{l}\text { Perusahaan } \\
\text { asuransi }\end{array}$ & $\begin{array}{l}\text { Premi } \\
\text { kredibilitas }\end{array}$ & $\bar{y}_{i}$ \\
\hline Allianz & 47,866 & 48,132 \\
\hline Csob & 3,360 & 3,170 \\
\hline Generali & 9,806 & 9,682 \\
\hline Koop & 60,453 & 60,848 \\
\hline Uniqa & 5,973 & 5,810 \\
\hline Wusten & 4,289 & 4,108 \\
\hline
\end{tabular}

Sumber: Data diolah (2021)

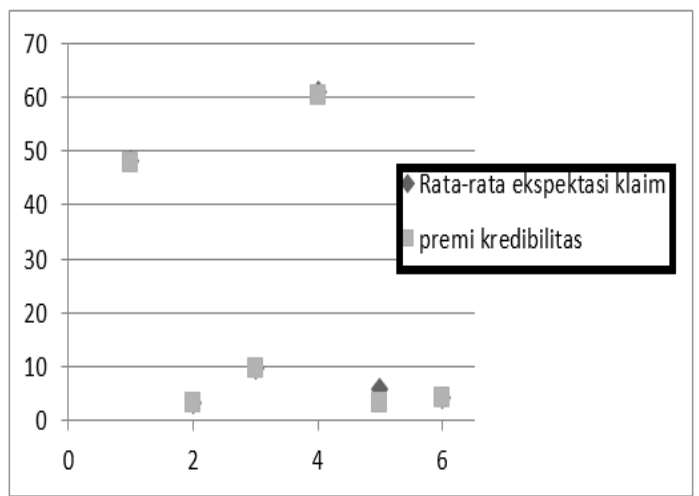

Gambar 1. Grafik Rata-rata eks pektasi klaim dan Premi kredibilitas

Dari Gambar 1 terlihat bahwa rata-rata ekspektasi klaim lebih besar dibandingkan dengan premi kredibilitas.

\section{KESIMPULAN DAN SARAN}

\subsection{Kesimpulan}

Kesimpulan yang diperoleh dalam penelitian ini, yaitu estimasi harga premi kredibilitas (dalam Euro) untuk perusahan asuransi Alianz, Csob, Generali, Koop, Unisqa, dan Wusten berturut-turut adalah sebagai berikut: 46,774811; 7,801307; 10,368991; 58,812250; 6,703035; dan 5,091605.

\subsection{Saran}

Untuk penelitian selanjutnya, disarankan untuk berupaya menempatkan anteseden empirical Bayes credibility theory model 1, untuk memperhitungkan harga premi kredibilitas asuransi umum lainnya misalnya asuransi kebakaran, pengangkutan, perjalanan, rancangan kapal, perkebunan, pertanian, pesawat terbang, satelit, mesin dan berbagai imbas kerugian kekayaan lainnya.

\section{DAFTAR PUSTAKA}

Chukwudum, Q. (2018). Credibility Premium Estimation of Insurance Claims in Nigeria. Archives-Ouvertes, 1(1), 1-14.

Herzog, T. N. 1996. Introduction to Crediblity Theory (Second Edi). Winsted: ACTEX.

Linda, \& Kubanova. (2012). Credibility Premiun Calculation in Motor Third-Party Liability Insurance. Advances in Mathematical and Computational Methods, 1(1), 259-263.

Otoritas Jasa Keuangan (2019). Statistik Peransuransian indonesia hhtp://ojk.go.id

Pham, M. H. (2014). Survival Analysis-Breast Cancer. Journal of Mathematical Modeling: One+ Two, 6(1), 4.

Satyahadewi, N., \& Mara, M. N. . (2013). Karakteristik Faktor Kredibilitas Pada Model Buhlmann Untuk Menentukan Premi. Jurnal Mipa, 36(1), 1. 